\title{
0 povo em fúria: a revolta urbana de 1925 em Fortaleza
}

\section{Eduardo Oliveira Parente*}

Resumo: Em 1925, a população trabalhadora de Fortaleza se revoltou contra as medidas postas em prática pela companhia inglesa Light and Power, que explorava o serviço de transporte público por bondes e produção de energia elétrica. Essas medidas envolviam a elevação das tarifas e mudanças no sistema de transporte (veículos de $1^{\mathrm{a}}$ e $2^{\mathrm{a}}$ classe e alteração nos horários). O protesto popular durou vários dias, alterando o cotidiano urbano. O presente artigo analisa os sujeitos envolvidos na revolta e as conexões desse episódio com o processo de ampliação - populacional e espacial do ambiente urbano, deficiência dos serviços públicos, aumento do custo de vida que atingiam a classe trabalhadora e sua luta pelo direito à cidade.

Palavras-chave: revolta; bondes; expansão urbana.

Abstract: In 1925, the working population of Fortaleza revolted against the measures implemented by the British company Light and Power, which operated the public transport service by trams and electric power production. These measures involved tariff increase and changes in the transportation system (first and second class cars and change in schedule). Popular protest lasted several days, changing the life of the city. This episode is linked to the enlargement process - population and space - of the urban environment, public services deficiency, increase the cost of living that hit the working class and their struggle for the right to the city.

Keywords: revolt; trams; urban sprawl.

A viagem inaugural, em 1913, do primeiro bonde elétrico (tramway) na capital cearense - substituindo os bondes movidos por tração animal - provocou um "grande alvoroço", segundo Raimundo de Menezes, memorialista da "Fortaleza Antiga". Muitos curiosos fizeram questão de transitar no novo equipamento e "só abandonavam o veículo, quando se acabava o dinheiro". ' Segundo o jornal Unitário, por outro lado, uma "massa de curiosos invadiu o carro" mesmo com "os protestos dos eletricistas ingleses". ${ }^{2}$ Fortaleza parecia dar mais um passo rumo

* Doutorando em História Social pela Universidade Federal do Ceará (UFC). E-mail: ed_parente@yahoo. com.br.

1 MENEZES, Raimundo de. Coisas que o tempo levou (crônicas históricas da Fortaleza Antiga). Fortaleza/São Paulo; HUCITEC, 1977, p. 43.

2 Unitário, Fortaleza, 28 set. 1913, p. 1. 
ao progresso com a chegada da eletricidade e dos tramways: "Não há [como] negar que a introdução dos bondes elétricos aqui, em Fortaleza, trouxe crescidas vantagens à população. Era esse melhoramento de há muito tempo almejado". ${ }^{3}$ No "imaginário da modernização" o bonde elétrico ocupava um espaço importante, sendo um signo dessa modernidade, especialmente devido ao fascínio sedutor da eletricidade, considerada uma "fonte de energia mais potente e higiênica, se comparada ao vapor e ao gás" e que "incorpora elementos simbólicos de um imaginário fascinado pela ciência e pelo seu 'ilimitado' poder".4

Entre 1913 e 1914, a "Ceará Tramway, Light and Power", companhia inglesa que passou a explorar em Fortaleza o serviço de produção de energia elétrica e de bondes, já havia eletrificado todas as linhas. Sem concorrência, a Light operava em caráter de monopólio o transporte público da capital. ${ }^{5}$ Os primeiros anos foram, podemos dizer, de regozijo e adaptação. ${ }^{6}$ Comemorava-se a introdução desse melhoramento e, aos poucos, foram surgindo demandas específicas. No Diário do Estado, por exemplo, encontramos solicitações "à digna e zelosa gerência da 'Light'" para que nos dias de corrida no Jóquei Club o número de bondes fosse ampliado para essa região. ${ }^{7}$

Nos anos 1920 o clima amistoso já estava ficando para trás. As queixas se tornavam comuns. Em 1923, o jornal A Tribuna reclamava do "imprestável material da 'Light \& Power'", destacando que "os bondes são sujos, sem conforto e nos dias de chuva os passageiros sofrem bastante". ${ }^{8}$ Em outra edição, o mesmo periódico reclamava que em certo dia "de maior movimento de toda a semana, diversos bondes dessa companhia ficaram parados em várias linhas, por falta de energia elétrica", acrescentando que o "número de bondes é por demais insuficiente (...) quando é certo que o movimento da cidade vai crescendo em grande proporção". 9

As críticas à companhia eram cada vez mais intensas, não poupando a inércia das autoridades: "Inúmeras, incontáveis mesmo, são as graves irregularidades da 'Light', que as pratica impunemente, sem que haja, nesta civilizada capital, uma única autoridade que tenha o ânimo de chamá-la ao cumprimento do dever"..

O jornal de orientação católica O Nordeste chegou a estampar a seguinte reclamação:

\begin{abstract}
Veículos servindo ao transporte urbano de todas as classes sociais, neles viajam promiscuamente as elegantes damas de nossa culta sociedade ao lado de sujos caipiras que lhes soltam ao rosto baforadas de charutos de vintém e, de quando em vez, sobre o soalho do carro, nauseabundas cusparadas. É uma situação muito desagradável para pessoas educadas e que se cultivam até mesmo as que só conhecem rudimentares preceitos de higiene.
\end{abstract}

3 Unitário, Fortaleza, 19 out. 1913, p. 2.

4 ROCHA, Amara Silva de Souza. "Modernas seduções urbanas: a eletrificação no Rio de Janeiro da Belle Époque." Anos 90, Porto Alegre, n. 14, dez. 2000, p. 202 e 203.

5 A iluminação pública (feita por combustores a gás) era monopolizada por outra empresa britânica: "Ceará Gás Company". O fornecimento de energia para residências era ainda muito tímido. Somente os mais abastados puderam contar, inicialmente, com luz elétrica. Perto do final dos anos 1920, a cidade passaria a contar, também, com serviço de ônibus.

6 Algumas regras e disposições foram definidas pela Câmara Municipal e divulgadas pela imprensa. Por exemplo: "Art. 1 - É proibido fumar nos três primeiros bancos dos carros de passageiros das linhas de Tramways; Art 2 - É proibido cuspir nos mesmos." Folha do Povo, Fortaleza, 23 nov. 1913, p. 1. Nem sempre tais regras eram, de fato, obedecidas.

7 Diário do Estado, Fortaleza, 29 ago. 1916, p. 1.

8 A Tribuna, Fortaleza, 17 ago. 1923, p. 2.

9 A Tribuna, Fortaleza, 28 ago. 1922, p. 2.

10 A Tribuna, Fortaleza, 17 out. 1923, p. 1. 
Sabemos que a Companhia não tem carros de $2^{\text {a }}$ classe; resignemo-nos, pois, quanto a isso, e esperemos que, um dia, ela possa satisfazer essa condição para servir razoavelmente seus passageiros de escol social. ${ }^{11}$

Próximo ao final do mês de setembro de 1925, a Light divulgava, pelas páginas da imprensa local, em um "Aviso ao Público",12 as mudanças que estaria iniciando brevemente no sistema de transporte urbano: instituição de classes diferenciadas no transporte público (bondes de $1^{\mathrm{a}}$ e $2^{\mathrm{a}}$ classe), alteração nos horários e elevação das tarifas nos veículos de $1^{a}$ classe. ${ }^{13}$ De certa forma, a súplica do periódico conservador - expressando, talvez, o desejo dos "passageiros de escol social" seria atendida poucos anos adiante.

Na sequência do comunicado seguia uma tabela indicativa dos horários de cada linha, constando a discriminação específica para cada tipo de veículo. Selecionamos três trajetos conforme a tabela a seguir:

\begin{tabular}{|c|c|c|c|}
\hline \multicolumn{2}{|c|}{ Linha da Praia } & \multicolumn{2}{|c|}{ Via Férrea } \\
\hline $1^{\text {a }}$ Classe & $6: 00$ & $1^{\mathrm{a}}$ Classe & $6: 00$ \\
\hline $2^{a}$ Classe & $6: 08$ & $2^{a}$ Classe & $6: 00$ \\
\hline $1^{\text {a }}$ Classe & $6: 17$ & $1^{\mathrm{a}}$ Classe & $6: 15$ \\
\hline $2^{\mathrm{a}}$ Classe & $6: 25$ & $1^{\mathrm{a}}$ Classe & $6: 30$ \\
\hline $1^{\text {a }}$ Classe & $6: 34$ & $2^{a}$ Classe & $6: 30$ \\
\hline $2^{\mathrm{a}}$ Classe & $6: 42$ & $1^{\mathrm{a}}$ Classe & $6: 45$ \\
\hline $1^{\text {a }}$ Classe & $6: 51$ & & \\
\hline
\end{tabular}

\begin{tabular}{cc}
\hline \multicolumn{2}{c}{ Estação } \\
\hline $1^{\text {a }}$ Classe & $6: 03$ \\
\hline $2^{\text {a }}$ Classe & $6: 15$ \\
\hline $1^{\text {a }}$ Classe & $6: 25$ \\
\hline $1^{\text {a }}$ Classe & $6: 35$ \\
\hline $2^{\text {a }}$ Classe & $6: 45$ \\
\hline $1^{\text {a }}$ Classe & $6: 55$ \\
\hline
\end{tabular}

Não era difícil perceber os problemas. No geral, todas as linhas apresentavam o mesmo princípio: preponderância dos veículos de $1^{\text {a }}$ classe, com tarifas mais elevadas, em detrimento daqueles de $2^{\text {a }}$ classe. O Nordeste destacava a necessidade de "ligeiros reparos" nos horários, que "não atendem às necessidades do tráfego intenso desta capital". Da mesma forma conviria também "um reparo sobre a distribuição dos bondes de $2^{\mathrm{a}}$, destinados a facilitar os pobres", pois "esse horário obrigará os pobres a andarem a pé, salvo a hipótese de poderem pagar o aumento das passagens. Ora, razoável seria aumentar o número de carros de $2^{\text {a }}$, para favorecê-los". ${ }^{14}$

O periódico colocava como opções pagar mais caro nos veículos de $1^{\text {a }}$ classe para chegar no horário ao destino desejado ou caminhar no seu deslocamento pela urbe. Para a população trabalhadora e pobre da capital, possivelmente, a questão seria compreendida de outra forma. Recusando a resignação ou o aumento dos gastos, a população optou por forçar a companhia a ceder às necessidades e interesses dos usuários.

\section{II}

A companhia inglesa, provavelmente, não esperava encontrar uma resistência tão tenaz às mudanças que estava iniciando. No dia 28 de setembro, o Jornal do Commercio noticiava que desde as primeiras horas da manhã vinha crescendo "um movimento popular de protesto contra o acréscimo nas passagens dos

11 O Nordeste, Fortaleza, 20 dez. 1922, p. 3.

12 O Nordeste, Fortaleza, 26 set. 1924, p. 1.

13 Em 1923 ocorreu a elevação da tarifa de energia e o debate sobre o aumento do preço das passagens dos tramways foi realizado em 1924. Aproximadamente um ano depois, tal resolução começava a ganhar implementação prática.

14 O Nordeste, Fortaleza, 28 set. 1925, p. 1. 
bondes". ${ }^{15}$ Esses primeiros sinais de agitação teriam partido principalmente dos estudantes do Liceu e de outros colégios. Por volta do meio-dia, porém, "já não só estudantes, senão também grande número de populares renovou as suas ruidosas manifestações de desagrado contra a Light". ${ }^{16}$ O Jornal do Commercio afirmava que neste momento "culminou a agitação com o movimento sempre contínuo da onda de protestantes", sendo que "na partida de cada tramway, que sai da Praça do Ferreira, a atordoada é violenta, sendo alguns tomados de assalto". ${ }^{17}$

O clima começava a ficar mais tenso. A agitação crescia com o avolumar de pessoas insatisfeitas. Todavia, na direção da Praça do Ferreira, centro nervoso da capital e local no qual se concentrava o maior número de manifestantes, uma "patrulha de cavalaria da Polícia Militar", comandada pelo tenente João Medeiros Bastos, "se movimentava para espaldeirar o povo". A ação foi qualificada pela imprensa como um "procedimento insólito, desarrazoado e arbitrário", no qual a responsabilidade cabia ao referido tenente, cuja atuação "apenas serviu para irritar os ânimos" e "exaltar o povo". O mesmo periódico arrematava:

Sem querer dar razão a desordens, que de modo algum se justificam, julgamos que a Light precisa modificar o sistema condenável que estabelecera.

Para atender aos interesses do público, a providência que se impõe é o tráfego simultâneo dos bondes de $1^{\text {a }}$ e de $2^{\text {a }}$ classe, para todas as linhas.

Só assim ficarão servidos os caixeiros, operários e outras classes cujos recursos não são tão fartos que deixem margem a uma tão rápida duplicação de despesas. ${ }^{18}$

O pelotão de cavalaria foi recolhido após ordem do governo e o tenente foi chamado para prestar esclarecimentos. Ao mesmo tempo, uma comissão foi formada para conferenciar com o presidente do Estado, desembargador Moreira da Rocha, na tentativa de estabelecer um acordo. Os bondes foram recolhidos no final da tarde e o tráfego foi totalmente suspenso.

Em sua edição do dia 29 de setembro, a imprensa relatava com mais detalhes os acontecimentos do dia anterior. Afirmava que o aumento do preço das passagens "provocou protestos violentos por parte do povo" e que durante todo o dia "registraram-se distúrbios". O povo invadia os veículos e "num gesto de revolta, esbandalhava-os, arrancando cortinas, quebrando balaústres, sinetas, lâmpadas" e completava: "diversos dos bondes novos foram grandemente danificados". O local de maior concentração, como já destacamos, era a Praça do Ferreira, ponto de confluência de várias linhas de bonde. As aglomerações se formavam na praça e nos pontos de parada dos veículos. Até mesmo o gerente da Light, Mr. Scott, "viu-se ameaçado pelo povo ao entrar no Posto de Bondes", só saindo do local "sob garantia de um pelotão de cavalaria". ${ }^{19}$

Ainda tratando dos acontecimentos do dia anterior, o jornal O Nordeste, afirmava que "se o preço causou desagrado, o novo horário adotado para os carros de 100 rs. revoltou a multidão". A movimentação popular e a violência do pelotão de cavalaria geraram uma "cena indescritível, de pânico e desespero". Como já destacamos, uma comissão foi formada em praça pública para dialogar

15 Jornal do Commercio, Fortaleza, 28 set. 1925, p. 4.

16 O Nordeste, Fortaleza, Fortaleza, 28 set. 1925, p. 4.

17 Jornal do Commercio, Fortaleza, 28 set. 1925, p. 4.

18 O Nordeste, Fortaleza, 28 set.1925, p. 4.

19 Jornal do Commercio, Fortaleza, 29 set. 1925, p. 4. 
com o governo estadual, sendo composta pelo advogado Alcides Gomes de Mattos, Euclides Themotheo, R. Ribas, Theophilo Cordeiro e Alpheu Aboim, todos recebidos rapidamente pelo chefe de Estado, desembargador Moreira da Rocha, em companhia de José Mattos Peixoto, secretário do Interior e advogado da Light. O advogado Gomes de Mattos, "expressando a vontade do povo", afirmou ao presidente do Estado que a Light "não podia exigir 200 rs. para os diminutos percursos existentes nesta capital". Afirmou ainda que, pelo contrato, a Light deveria colocar reboques nos veículos de $1^{a}$ classe, o que não estava sendo feito e, "para enganar o povo", teria posto em circulação bondes velhos, "ditos de $2^{\text {a }}$ classe", com um "horário de 20 e mesmo 40 minutos" de diferença, "justamente nas horas em que mais se tornavam precisos esses carros".

A fala do advogado foi referendada pelos demais membros da comissão. O presidente do Estado garantiu que estudaria o problema e tentaria atender as demandas, mas alertou que não admitiria que "o povo cometesse depredações". No coreto da Praça do Ferreira, o advogado Gomes de Mattos e os demais membros da comissão relatavam à multidão o que ficou decidido, sendo as falas interrompidas pelo "protesto do Sr. Teixeira Gueiros" afirmando serem "as medidas do governo ilusórias", pois estariam os governantes de conluio com a companhia, propondo o prosseguimento do quebra-quebra. Um grupo, rapidamente, tomou um dos bondes estacionados e "reduziram-no a frangalhos. Cortinas, vidros, campainhas, lâmpadas e todos os objetos fáceis de quebrar foram arrebentados". Diante da ação, o capitão Espinheiro, com autorização superior, iniciou a prisão dos mais exaltados e, frente à revolta dos demais, contrários a esta atitude, deu ordem para seu contingente agir, e os praças "carregaram sobre o povo". Houve correria e fechamento dos cafés e das casas comércio, restando o saldo de várias "cabeças rachadas, costas contundidas e braços escoriados". Por fim, "o mais movimentado trecho de Fortaleza ficou reduzido ao silêncio"..20

Mesmo com a formação de uma comissão, composta por elementos de destaque na vida pública da cidade, a opção por um enfrentamento direto foi mantido como tática preferencial de ação, pelo menos por uma parcela dos manifestantes. No caso, a desqualificação dessa forma específica de ação coletiva pelo chefe de Estado já apontava para os mecanismos coercitivos e violentos, postos rapidamente em prática pelas forças de segurança para debelar o movimento popular. Se na primeira reação policial, qualificada como arbitrária, o governante afirmou não ter autorizado semelhante atitude, agora estava certo o pouco compromisso e tolerância do governo em relação à ação espontânea da multidão. Frente à negociação coletiva tumultuosa da população - rompendo o que eram considerados mecanismos legais de representação e negociação - só haveria uma resposta: o uso imediato das forças policiais. Ao mesmo tempo, era perceptível a desconfiança da população quanto a medidas provenientes da Presidência do Estado e era evidente que não existia qualquer coordenação unificada nas manifestações.

A gerência da Light, por sua vez, não estava disposta a se submeter à vontade popular, só aceitando a circulação dos tramways com as tarifas e os horários estabelecidos. A usina e a estação de bondes passaram a ser guardadas por contingentes policiais. Só eram visíveis pequenos protestos (vaias) na Praça do Ferreira, na qual se concentrava o maior número de policiais. Os estudantes, primeiros protagonistas da revolta, "tratavam de realizar o enterro do gerente 
da Light" - prática simbólica de desagrado e crítica que até hoje continua sendo utilizada em diversos movimentos. Durante todo o dia 29 de setembro, o tráfego permaneceu paralisado, na tentativa de evitar maiores tumultos, e a polícia tratava de desfazer os "agrupamentos que se formam". ${ }^{21}$

No terceiro dia o caso continuava sem solução. Sobre o assunto, o Jornal do Commercio publicava:

\begin{abstract}
O povo não se conforma com o novo horário dos bondes e exigem [que] andem conjuntamente nas linhas carros de $1^{\mathrm{a}}$ e $2^{\mathrm{a}}$ classe, já que a companhia inglesa aumentou o preço das passagens para os primeiros, conservando o preço antigo para os últimos que servirão às classes pobres. A Light, por sua vez, alega que a deficiência de carros não Ihe permite satisfazer a exigência do povo e, por isso, conserva o seu horário.

E o resultado é estar a cidade desde a tarde de anteontem sem o tráfego dos bondes, que ainda hoje não circularão. ${ }^{22}$
\end{abstract}

Ao mesmo tempo, na Phenix Caixeiral, "poderosa agremiação da classe caixeiral de Fortaleza", a diretoria deliberou apoiar, "de maneira pacífica", o atual movimento. Uma comissão composta por membros dessa associação foi formada para dialogar com o governo estadual. Nas ruas, alguns boletins, qualificados pela imprensa como "exaltados", eram distribuídos. Um deles é reproduzido:

A questão dos bondes e qual deverá ser a atitude do povo.

- Com vistas ao sr. fiscal da Prefeitura, perante a arrogante Empresa.

Perante a Prefeitura Municipal, a Light, companhia inglesa que no Ceará explora o serviço de tração elétrica, tem convencionado o seguinte contrato:

'A empresa inglesa fará circular carros, ao preço de DUZENTOS RÉIS cada passagem, sob condições de que sejam mais confortáveis que os atuais, passando estes a figurar como de SEGUNDA, ao preço de CEM RÉIS.'

No entanto, com arrogante desrespeito às autoridades da terra, a Light fez apenas aumentar os preços dos carros atuais que, pela força do contrato, deveriam figurar como carros de segunda.

Nessa situação, o povo que é quem paga imposto, só uma atitude deve assumir: fazer a convenção estabelecida com a prefeitura, isto é, pagar cem réis de passagem, nos atuais tipos de veículos, pouco importando que sejam eles pintados com qualquer uma das cores do arco-íris, ou então, se o governo municipal quer sanar o mal, obrigue a Companhia a fazer circular, tanto carros de $\$ 100$, quantos forem os de duzentos. ${ }^{23}$

Percebemos um esforço para legitimar a ação popular: se a companhia não está cumprindo exatamente o que reza a sua convenção com a prefeitura, por que o povo deveria obedecer? E mais: ao povo é facultado o direito de fazer cumprir a letra contratual de "pagar cem réis de passagem nos atuais tipos de veículos", já que as autoridades públicas não demonstram capacidade ou vontade para forçar a companhia por em tráfego bondes de $1^{\mathrm{a}}$ e $2^{\mathrm{a}}$. A referência feita à coloração diferenciada deve-se ao fato de que os veículos eram identificados pela pintura:

21 O Nordeste, Fortaleza, 29 set. 1925, p. 4.

22 Jornal do Commercio, Fortaleza, 30 set. 1925, p. 4.

23 O Nordeste, Fortaleza, 30 set. 1925, p. 4. (Destaques no original). 
"O de $2^{\text {a }}$ classe era prateado e o de $1^{\text {a }}$ classe era pintado de verde". ${ }^{24}$

Diante do impasse, "boatos" começam a ser difundidos pela cidade: falava-se que a Sociedade Deus e Mar $^{25}$ prestaria seu apoio ao movimento e que os motorneiros e condutores ameaçavam entrar em greve. Tal paralisação não ocorreria nesse momento, pois, para evitar um acúmulo de dificuldades, que obrigaria a enfrentar simultaneamente uma revolta popular e uma greve, a Light prometeu aumentar os salários dos trabalhadores do tráfego de bondes.

As reuniões entre o governo e os representantes da companhia, por sua vez, acenavam com um possível acordo. O presidente do Estado propunha o restabelecimento do bonde das 5h3omin para a via férrea e que nos horários de maior movimentação - durante o início da manhã, no horário do almoço e ao fim da tarde - houvesse bondes de $1^{\mathrm{a}}$ e $2^{\mathrm{a}}$ simultaneamente, sendo autorizado o tráfego alternado nos demais horários. O acordo fechado de "última hora", no entanto, previa as seguintes medidas: "Pelo horário antigo, recusado pelo povo, havia 26 bondes em tráfego, sendo 11 de $2^{\text {a }}$ classe e 15 de $1^{\text {a". }}$. Como solução, a companhia faria circular "13 bondes de $2^{\mathrm{a}}$ e 13 de $1^{\mathrm{a}}$ ", equiparando, portanto, 0 número de veículos. Previa-se ainda a circulação alternada dos mesmos a partir das $6 \mathrm{~h}$ da manhã, sendo restabelecidos aqueles das 5 h3omin com destino à estação de trens. Às "11h e às 17h partirão da Praça do Ferreira, para F. Vieira, Estação, Mororó, Matadouro e Outeiro, bondes de $2^{\mathrm{a}}$ simultaneamente com os de $1^{\mathrm{a}}$ ". Para $O$ Nordeste, em tom de exortação, o povo deveria "aguardar calmamente o resultado dessas modificações", sendo as mesmas "fruto do interesse e boa vontade que o governo vem demonstrando nessa questão em favor da população de Fortaleza", cabendo a todos "esperar confiantes na ação do poder público". ${ }^{26}$

Pelo que fica exposto, o acordo entre o governo e a empresa foi cercado de meias medidas: equiparação dos veículos em ambas as classes, permissão para o tráfego alternado na maior parte dos horários - contrário à principal exigência popular - com a única concessão de simultaneidade em dois horários de intenso fluxo (ao meio-dia e final da tarde, excluindo o início da manhã) restrito, porém, a algumas linhas.

Tanto o Jornal do Commercio quanto O Nordeste partem para uma defesa irrestrita dos atos governamentais e dos dispositivos legais - únicos supostamente legítimos - para se solucionar corretamente o dissídio. A população logo demonstraria compreender a questão de outra forma. Expressaria seu descontentamento, principalmente, por meio de ações, contrariando as expectativas de ambos os jornais - que clamavam pela paciência e resignação - e dos governantes que esperavam que seu acordo findasse os distúrbios.

No dia $1^{\circ}$ de outubro, logo cedo, com a retomada da circulação dos bondes, "começaram a surgir os protestos". Na Praça do Ferreira ocorriam "arruaças e vaias" e "os ajuntamentos foram pouco a pouco aumentando". Da diversidade de grupos alguns se destacavam, como aqueles "chefiados pelo Dr. Alcides Gomes de Mattos, [que] percorriam a praça, em manifestações de desagrado". Outros pediam o fechamento dos estabelecimentos comerciais e assim "o comércio e os cafés trancaram suas portas". O governo convocou ao palácio o advogado Alcides

24 ADERALDO, Mozart Soriano. História abreviada de Fortaleza e crônicas sobre a cidade amada. Fortaleza: Edições UFC/Casa de José de Alencar, 1993, p. 41.

25 A Sociedade Deus e Mar, fundada em 1912, representava os marítimos e tinha como objetivo "beneficiar, instruir e promover a defesa dos seus associados". Contava, em 1925, com aproximadamente 703 sócios. Almanaque do Ceará para o ano de 1925, Fortaleza: Tipografia Gadelha, 1925, p. 201.

26 O Nordeste, Fortaleza, 30 set. 1925, p. 4. 
Gomes de Mattos "a quem explicou as providências que tomara no sentido de amparar os interesses públicos", na esperança que o jurista "esclarecesse ao povo essa atitude, fazendo-lhes ver como o novo horário atendia às suas legítimas aspirações". Ao mesmo tempo, foram convocados representantes da Phenix Caixeiral e da Associação dos Merceeiros para os mesmos esclarecimentos. O presidente estadual reclamava da situação da cidade "perturbada por arruaças". ${ }^{27}$

Enquanto isso, nas ruas, os ânimos ficavam tensos. Tentando impedir a depredação dos tramways, um disparo - supostamente casual - teria sido efetuado pelos policiais.

O povo tomou-se de pânico, julgando que o disparo tinha sido feito sobre a massa popular. Nessa mesma persuasão, o Sr. Firmino Henrique de Oliveira, exaltando-se, portou-se de modo inconveniente, insuflando o povo, pelo que foi convidado a comparecer à delegacia de polícia, onde permaneceu algumas horas, sendo depois transportado para sua residência em companhia do tenente Montenegro. ${ }^{28}$

Ao mesmo tempo, "um vigoroso grupo de exaltados", inicialmente liderados pelo advogado Gomes de Mattos, dirigia-se "para os lados da praia, a fim de obter o auxílio da Deus e Mar". O grupo, não mais contando com a presença do jurista - que, como sabemos, havia sido convocado ao Palácio do Governo -, prosseguia no seu intento, sendo interceptado "por um esquadrão de cavalaria", sob as ordens do capitão Espinheiro. O oficial teria pedido que "em nome do presidente do Estado e do bem-estar da família de cada um, voltassem para suas casas ou seus trabalhos". A multidão dispersou-se. O Nordeste afirmou ter se tratado de um "pedido cortês", o que parece muito pouco provável. Diante do avolumar dos protestos e das constantes ameaças de maiores enfrentamentos da massa popular com as forças policiais, as aulas do Liceu e demais estabelecimentos de ensino foram canceladas. Outros grupos de populares, por sua vez, tentaram invadir a residência do gerente da Light, Mr. Scott, não logrando êxito. As detenções policiais se avolumavam constantemente, sendo efetuadas prisões dos "mais exaltados", como, por exemplo, do indivíduo Budião Pereira, que "andava distribuindo boletins" e de outro rapaz não identificado "que andava batendo nos bondes, além de conduzir consigo um revólver". Ao final do dia reduziram-se os incidentes. A polícia continuava o "patrulhamento das ruas". Somente alguns poucos "ajuntamentos" eram notados, promovendo "algumas vaias".29

O dia seguinte iniciou relativamente calmo. O Nordeste continuava alardeando pelas suas páginas que o acordo estabelecido entre o governo e a companhia atendia completamente aos "reclamos da população" e afirmava que agora seria "dever do povo" cessar os distúrbios, resguardando o direito de não "transitar nos bondes de $1^{\text {a }}$ classe". 30

Os membros das diretorias das associações ligadas às atividades comerciais - Centro dos Importadores, Associação Comercial, Associação dos Merceeiros e Phenix Caixeiral - fizeram uma reunião conjunta, resolvendo os presentes delegar poderes aos respectivos presidentes para se entenderem com o presidente do Estado. Compareceram ao Palácio do Governo os Srs. José Gentil, presidente da Associação Comercial; João Lopes, do Centro dos Importadores; José Ferreira

27 O Nordeste, Fortaleza, 1 out. 1925, p. 1.

28 Jornal do Commercio, Fortaleza, 1 out. 1925, p. 4.

29 O Nordeste, Fortaleza, 1 out. 1925, p. 1.

30 O Nordeste, Fortaleza, 2 out.1925, p. 4. 
Leitão, dos Merceeiros; Vicente Roque, da Phenix Caixeiral. As duas primeiras reuniam alguns dos mais poderosos e influentes capitalistas locais, a Associação dos Merceeiros agrupava pequenos proprietários do comércio varejista e a Phenix Caixeira ${ }^{31}$ reunia os trabalhadores do comércio, caixeiros, possuidores de uma longa tradição associativa que remonta ao século XIX, quando foi fundada a referida agremiação, sendo a única propriamente operária desse grupo (se aqui entendermos operários como todos os trabalhadores manuais urbanos).

Em uma reunião "tumultuosa" na Phenix, requerida por "mais de cem sócios", contando com o comparecimento de "incomputável número" de associados, a situação ganhava outra avaliação. Iniciando os trabalhos, o presidente Vicente Roque cedeu a palavra ao Sr. Oscar Castello Branco, que "pediu calma aos seus consócios e confiança na ação do poder público". Em seguida falou o Sr. Carlos Pinho "reclamando a defesa dos interesses dos caixeiros, que, ao seu ver, estavam ainda sem resguardo". No mesmo sentido se pronunciaria, "em linguagem exaltada", o jovem Mozart Medina. Por fim, o Sr. Paes de Castro propôs a constituição de uma comissão para se entender com as autoridades, declarando que "a Phenix não concordava, ainda, com o novo horário e insistia pela sua reclamação de bondes de $2^{\mathrm{a}}$ simultâneos com os de $1^{\mathrm{a}}$. $^{32}$

O aumento da repressão policial contribuiu para o arrefecimento das ações populares. Apesar disso, era noticiado que as animosidades contra a Light prosseguiam sem desânimo com a abstenção dos usuários de utilizar os veículos de $1^{\text {a }}$ classe. Todavia, novos acontecimentos modificavam os rumos do movimento popular: duranteamadrugadaum "grupo deexaltados, oupessoas parceladamente, entenderam de usar meios violentos". Em um ato qualificado pela imprensa como "criminoso", puseram, próximo ao final da linha do Alagadiço, "pequena carga de dinamite, que, à passagem de um bonde de $2^{\text {a }}$ classe, explodiu, quebrando uma das rodas do mesmo". 33 Nenhum passageiro foi ferido. Fica evidente que uma nova forma de ação estava sendo posta em prática: se antes a população demonstrava seu desagrado em um movimento público direto com depredações dos bondes da Light, agora, um grupo imprimia nova dimensão, uma ameaça à propriedade da companhia, ao mesmo tempo em que arriscava a integridade física dos usuários, o que em hipótese alguma ocorria nas iniciativas anteriores. A mudança se deve, provavelmente, ao avolumar da vigilância policial que tornou muito difícil os protestos diretos. Diante dessa dificuldade, alguns grupos devem ter optado por uma forma violenta de sabotagem. Todavia, essa mudança de orientação não parece ter contribuído - ao contrário do que seus promotores esperavam - para alavancar o ímpeto de revolta da maioria da população.

As suspeitas policiais quanto aos responsáveis pela colocação da dinamite nos trilhos do bonde começaram a recair sobre os autores dos boletins "incendiários" que há vários dias eram distribuídos pela urbe. Rapidamente foram publicadas determinações do chefe de polícia aos "proprietários de tipografias", advertindo aos mesmos que "não devem ser distribuídos avulsos impressos sem que neles se declare, para os fins legais, o nome do estabelecimento gráfico onde

31 Fundada em 1891, a Phenix Caixeiral era uma das mais prósperas associações de trabalhadores do Ceará. Possuía sede própria, biblioteca com mais de três mil livros aberta para sócios e ao público em geral, oferecia serviços médicos para associados e escola de comércio. Sobre a formação da sociedade, sua forma de atuação e princípios gerais ver: OLIVEIRA, Francisco de Assis Santos de. "Os Caixeiros no Ceará: trabalho e educação na Revista Phenix, 1891-1916" (Dissertação de mestrado em História, Universidade Federal do Ceará, 2005), especialmente o capítulo 1.

32 O Nordeste, Fortaleza, 2 out. 1925, p. 4.

33 O Nordeste, Fortaleza, 5 out. 1925, p. 1. 
são confeccionados",34 sendo passível, em caso de desobediência, a apreensão dos exemplares e instauração de processo legal sobre os proprietários e autores. Apertava-se, dessa forma, o cerco sobre os articuladores dos boletins.

Obviamente não podemos aceitar como certo que os autores dos boletins fossem exatamente os mesmos que instalaram o explosivo. Os panfletos eram variados e, portanto, podem ter sido produzidos e confeccionados por pessoas e grupos diferenciados. Por exemplo, O Nordeste noticiava que durante toda a segunda-feira, dia 6 de outubro, "circularam vários boletins incentivando a greve pacífica". Desse conjunto, entretanto, se destacava um impresso "que prevenia a população contra futuros atentados nos bondes"; "Nesse papelucho afirmavase mesmo ser necessário o sangue cearense para consecução da vitória contra a Light". Esse último não trazia as especificações exigidas pelo chefe de polícia, o que reforçava as suspeitas policiais, ao mesmo tempo em que nos é permitido afirmar que a autoria dos boletins se devia a grupos variados, que não necessariamente compartilhavam dos mesmos métodos de ação. No mesmo dia, na linha da Praia de Iracema, seria encontrado "um enorme petardo, pesando quase um quilograma". O explosivo não chegou a ser detonado. ${ }^{35}$

Seja como for, o movimento popular perdeu intensidade. As manifestações públicas de protesto perderam energia e escassearam. Mesmo na Phenix Caixeiral, conforme noticiou o Jornal do Commercio, foram declarados "nulos todos os atos que ultimamente desprestigiaram o Sr. Vicente Roque, presidente da Sociedade, a propósito da questão da Light", findando o "movimento partidário que reinava no seio da Sociedade". ${ }^{36}$ Podemos interpretar o "fim" da revolta a partir de dois motivos básicos. Em primeiro lugar, a forte repressão promovida pelas forças de segurança, sob as ordens governamentais, limitou as possibilidades para o prosseguimento das ações diretas empreendidas pela população. Em segundo lugar, o início de ações mais violentas, que ameaçavam a própria população, ultrapassou os limites morais e legítimos compartilhados pela maioria do povo. Decerto os envolvidos nas manifestações de rua promovidas durante aqueles dias julgavam apropriadas as depredações contra os bens da companhia como mecanismo de pressão, e mesmo o enfrentamento com a polícia em alguns casos. Mas arriscar a vida das pessoas que utilizavam os bondes era totalmente inaceitável. Ao romper esse limite, os indivíduos que promoveram a instalação dos explosivos não conseguiram angariar apoio social.

III

Ahistoriografiadoprotestopopular, especialmentenoqueserefereàs revoltas urbanas, recebeu grande impulso a partir dos aportes teóricos e metodológicos da história social. ${ }^{37}$ Contribuições como as de Eric Hobsbawm, George Rudé, Edward Thompson, entre outros, ofereceram novos enfoques que permitiram tratar tais movimentos como parte da dinâmica das sociedades nos quais ocorreram, superando a visão que taxava tais protestos como "irracionais" ou desprovidos de conteúdo político. O protesto social dos grupos subalternos passou a ser analisado

34 Jornal do Commercio, Fortaleza, 6 out. 1925, p. 1.

35 As investigações policiais conduziram à Tipografia Popular e ao nome do Sr. Clínio Porto, como possível autor do boletim. $O$ inquérito, todavia, não conseguiu provar a conexão entre o suspeito de autoria do boletim e a execução do plano dos explosivos. O Nordeste, Fortaleza, 6 out. 1925, p. 4.

36 Jornal do Commercio, Fortaleza, 9 out. 1925, p. 2.

37 PAMPLONA, Marco. "A historiografia sobre o protesto popular: uma contribuição para o estudo das revoltas urbanas". Revista Estudos Históricos, Rio de Janeiro, v. 9, n. 17, p. 215-238, jul. 1996. 
como possuindo lógica própria, noções legitimadoras e objetivos mais ou menos definidos - embora muitos dos seus participantes tivessem dificuldade de expor publicamente e sistematicamente as reivindicações desejadas. No Brasil, várias pesquisas se debruçaram sobre momentos de revolta popular, sendo a Revolta da Vacina, no Rio de Janeiro, um episódio quase paradigmático nesse sentido. Nicolau Sevcenko, ${ }^{38}$ José Murilo de Carvalho ${ }^{39}$ e Leonardo Affonso de Miranda Pereira, ${ }^{40}$ por exemplo, analisaram essa impressionante revolta na capital do país. ${ }^{41}$

Tomando como parâmetro inicial as questões propostas por George Rudé42 acreditamos ser possível montar um quadro interpretativo satisfatório para a compreensão da revolta e seu significado.

Durante vários dias, a população demonstrou sua profunda insatisfação, mas não de forma indiscriminada. Os distúrbios não foram cegos. Podemos identificar, claramente, um padrão nas ações da multidão: atacavam preferencialmente os bondes, que devido sua limitada mobilidade se tornavam alvos fáceis. Eric Hobsbawm já havia notado essa característica dos bondes enquanto um alvo primordial nas insurreições urbanas:

a experiência demonstra que, entre as formas de transporte urbano, os bondes são, (...), extraordinariamente convenientes para os insurretos; em parte porque o aumento de suas tarifas, que tende a afetar todos os pobres simultaneamente, é um precipitador muito natural dos distúrbios e em parte porque esses enormes veículos, quando incendiados ou virados, podem facilmente bloquear ruas e interromper o tráfego. ${ }^{43}$

Era uma forma de demonstrar nitidamente o desagrado em relação às medidas da Light e, ao mesmo tempo, provocar prejuízos à companhia. A população adotava como estratégia uma "negociação coletiva através da arruaça",44 empregando ações diretas como instrumento de pressão. Em nenhum momento, qualquer pessoa foi ferida pelos amotinados durante o quebra-quebra, exceto nos casos de enfrentamento com a polícia. A única ameaça real promovida pela população revoltosa a um indivíduo foi direcionada para o gerente da Light, E.M.O. Scott, o que mais uma vez evidencia a seletividade dos ataques. Não havia dúvida que a companhia estrangeira - seu patrimônio em primeiro lugar e seus administradores em seguida - era o alvo da multidão.

Devemos ressaltar, novamente, que não houve qualquer forma de planejamento da revolta. Os grupos envolvidos estavam unidos por um mesmo

38 SEVCENKO, Nicolau. A Revolta da Vacina: mentes insanas em corpos rebeldes. São Paulo: Brasiliense, 1984.

39 CARVALHO, José Murilo de. Os bestializados: o Rio de Janeiro e a República que não foi. São Paulo: Companhia das Letras, 1987.

40 PEREIRA, Leonardo Affonso de Miranda. As barricadas da Saúde: vacina e protesto popular no Rio de Janeiro da Primeira República. São Paulo: Editora Fundação Perseu Abramo, 2002.

41 Logicamente não é nosso objetivo compulsar e comparar a vasta bibliografia sobre as revoltas urbanas no Brasil e nem seria possível tal empreitada, considerando que escaparia dos objetivos propostos no presente artigo e o limite de espaço.

42 Segundo esse autor, é necessário situar o fato no seu devido contexto histórico, efetuando um relato adequado dos acontecimentos; identificar quais as formas específicas de ação da multidão, quais eram os alvos preferenciais, o que permite descobrir motivações, finalidades e ideias subjacentes; verificar a eficiência das forças de repressão; por fim, quais as possíveis consequências. RUDÉ, George. A Multidão na História. Rio de Janeiro: Campus, 1991, p. 9-10.

43 HOBSBAWM, Eric. "Cidades e Insurreições". In: ___ . Revolucionários: ensaios contemporâneos. $3^{\mathrm{a}}$ ed. Rio de Janeiro: Paz e Terra, 2003, p. 222. Ainda esse mesmo autor alerta para o fato que a eficácia de um motim ou insurreição depende de três fatores: "a facilidade de mobilizar os pobres, a vulnerabilidade dos centros de autoridade a estes e a facilidade com que podem ser reprimidos".

44 HOBSBAWM, Eric. "Os Destruidores de Máquinas". In: do operariado. Rio de Janeiro: Paz e Terra, 1981. . Os Trabalhadores. Estudos sobre a história 
objetivo e contra um antagonista comum, as formas adotadas para alcançar estes mesmos objetivos podiam variar de grupo para grupo. As expressões usadas corriqueiramente pela imprensa são bastante reveladoras desse aspecto: "agrupamentos" e "ajuntamentos", o que aponta para a constituição informal de grupos sem que houvesse qualquer tipo de organização prévia. Os trabalhadores já se encontravam esporadicamente, mas cotidianamente, tanto nos pontos de embarque e desembarque dos veículos quanto dentro dos bondes durante o trajeto de casa para o trabalho ou do trabalho para casa, o que tornava tais ocasiões e lugares propícios para um bate-papo rápido ou para conversas um pouco mais demoradas, no qual se trocavam informações, se contavam pilhérias e se reclamava das dificuldades da vida. É bem possível, portanto, que tais momentos de sociabilidade informal possam ter contribuído para gerar afinidades que colaboraram na formação de alguns desses "ajuntamentos" e "agrupamentos", pelo menos no início da revolta. Como vimos, a Praça do Ferreira, no coração da cidade, na qual se entroncavam as mais diversas linhas de bondes (e respectivos pontos de embarque/desembarque), foi o palco principal dos protestos.

As lideranças eram, em sua maioria, fugazes - com exceção do advogado Gomes de Mattos, sobre quem teremos mais a falar. Um líder poderia surgir no momento, no calor dos acontecimentos, estimular e participar de uma determinada ação e não mais tornar a ter um papel de destaque. ${ }^{45}$ Vimos alguns desses durante a narrativa: o Sr. Teixeira Gueiros, que protestou e considerou ilusórias as promessas e medidas do governo, sendo acompanhado em sua revolta por vários indivíduos; o Sr. Firmino Henrique de Oliveira, que se revoltou contra o que considerou ser um ato arbitrário dos policiais; o indivíduo Budião Pereira, que foi detido enquanto distribuía boletins pela cidade; e um jovem, não nomeado, também detido por bater nos bondes e portar um revólver; e tantos outros anônimos que deram sua cota de esforço, compondo a multidão de revoltosos.

Por vezes, considerou-se que o surgimento da política moderna, com eleições, constituição de novas solidariedades entre as classes subalternas, com a formação de sindicatos e associações em geral, representariam a superação das formas anteriores de expressar descontentamento social (revoltas, motins, etc.). A passagem, portanto, de formas transitórias de protesto para formas duradouras e organizadas institucionalmente, capazes de construir as reivindicações em novos termos e de forma sistemática. A análise da revolta de 1925 permite matizar essa visão e rejeitar a hierarquização dos movimentos sociais. As associações não tiveram qualquer papel na preparação ou detonação das agitações e apresentaram dificuldades para impor uma determinada visão dos acontecimentos ou definir uma conduta durante o desenrolar do protesto. No caso da Phenix, por exemplo, a eclosão da revolta fez aflorar as divisões internas preexistentes.

Devemos destacar também que as formas de luta por meio de instrumentos legais e ações diretas não são excludentes, podendo ser implementadas de forma combinada. ${ }^{46}$ Exemplo paradigmático desse tipo de escolha, transitando entre ambas as formas de pressão, foi a postura adotada pelo advogado Gomes

45 Esse padrão se repete em vários outros episódios, nos quais as pretensas lideranças podem perder a capacidade de efetivamente conduzir os acontecimentos, sendo surpreendidos pelo ímpeto da revolta popular, como demonstra a historiografia que citamos para outros casos.

46 Thompson argumenta, para o caso do movimento luddista, na Inglaterra, que as formas constitucionais e violentas de atuação podiam (e eram) praticadas de forma intercambiável. Em algumas ocasiões, a pressão direta só era exercida quando falhavam os trâmites legais, ou como estratégia para acelerar uma medida jurídica favorável aos trabalhadores. Ver: THOMPSON, Edward. A formação da classe operária inglesa, v. 3: A força dos trabalhadores. Rio de Janeiro: Paz e Terra, 1987, p. 88-180. 
de Mattos, figura de liderança reconhecida por parte dos revoltosos. Ao mesmo tempo em que participava de grupos que tentavam efetuar o fechamento das casas comerciais e construir laços com agremiações operárias contra as medidas da Light, por exemplo, atuava como negociador junto ao governo estadual. Ao que parece, o jurista esperava reinserir a temática dos direitos populares na pauta de discussão governamental. Para alcançar esse intento, formas de pressão direta poderiam ser bastante válidas. Ou seja, se o Estado não atuava de forma coerente, defendendo os interesses legítimos da população, era cabível forçar o governo a tomar iniciativa ou, em última instância, o próprio povo, autonomamente, poderia efetuar a justiça.

Nesse sentido, somos inevitavelmente compelidos a tentar esboçar uma identificação dos "rostos na multidão". Qual seria, de fato, a composição social da massa de insurretos? Aos poucos, reunindo fragmentos de informação insuficientes, sem dúvida, mas nem por isso desprovidos de valor - podemos montar um panorama desse variado leque de personagens. A imprensa não teve dificuldades ao afirmar que os protestos iniciais partiram de estudantes, em especial alunos do Liceu. Esse grupo seria engrossado por elementos oriundos de outras procedências: "caixeiros, operários e outras classes" 47 seriam os mais prejudicados pelas medidas da Light, logo, seriam os prováveis protagonistas da revolta. Em outra ocasião afirmava-se peremptoriamente: "Nas horas em que os empregados do comércio, operários e jornaleiros vão ao trabalho ou dele saem, faltavam completamente os carros de $2^{\text {a }}$ classe". ${ }^{48}$ Mais uma vez são melhor definidos os grupos prejudicados e, portanto, os mais propensos a atos de rebeldia e contestação. Nesse grupo são inseridos, basicamente, segmentos da classe trabalhadora, para os quais a importância do transporte público era cada vez maior. Ao mesmo tempo, como destaca George Rudé, para identificarmos uma multidão, devemos complementar o que foi possível apurar, a partir de relatos de observadores, "com amostragens dos mortos, feridos ou presos em agitações", lembrando sempre que tais "amostras devem ser tratadas com cuidado, pois quase sempre são bastante pequenas para que possamos tirar delas conclusões gerais". ${ }^{49}$ Ciente dessa dificuldade, podemos observar a menção da prisão do phenixta Aécio Hollanda "por se exceder no seu entusiasmo", 50 sendo liberado após o comparecimento de uma comissão à delegacia de polícia. Ou ainda, o depoimento à imprensa do também sócio da Phenix, Raymundo Nonato de Freitas, garantindo que quaisquer "excessos cometidos nas ruas desta capital, por ocasião das manifestações populares" não teriam partido do grupo de phenixtas do qual fazia parte, garantindo que os mesmos "não tiveram a intenção de atacar a residência do gerente da Light", tampouco de usar meios violentos "para obter o fechamento do comércio". ${ }^{51}$ Apesar do objetivo evidente desse depoimento fosse isentar qualquer integrante da Phenix Caixeiral de participação nas ações delineadas, acaba por revelar que os mesmos tiveram uma grande e constante atuação em várias ações ${ }^{52}$ desenvolvidas "nas ruas desta capital". Além do mais, conforme analisamos, no interior mesmo da Sociedade surgiram divergências de procedimentos, com uma crítica à iniciativa do presidente da

47 O Nordeste, Fortaleza, 28 set.1925, p. 4.

48 O Nordeste, Fortaleza, 29 set. 1925, p. 4.

49 RUDÉ. A Multidão na História, p. 12.

50 Jornal do Commercio, Fortaleza, 30 set. 1925, p. 4.

51 O Nordeste, Fortaleza, 2 out. 1925, p. 4.

52 Situação similar foi identificada por Leonardo Pereira para o caso carioca: caixeiros tiveram grande participação na revolta de 1904. PEREIRA, As barricadas da Saúde, p. 58 e 61. 
agremiação em seu entendimento com o governo estadual, sem que antes fosse devidamente efetuada uma consulta à classe. Isso significa uma forte tendência democrática no interior da agremiação, que por aquela época já era marcada por uma burocratização em suas atividades e forte aproximação com os poderes constituídos.

Falta esclarecer um pouco mais as motivações da revolta. Afirmar que a causa dos protestos se deveu à elevação das tarifas e problemas no horário dos bondes é o começo da resposta. Devemos mobilizar outras variáveis, inserindo esse episódio em um quadro mais amplo envolvendo a luta contra a carestia e por direitos. Uma comparação com outros episódios pode auxiliar a identificar padrões, semelhanças e diferenças.

Marco Antonio Sávio53 analisando a revolta ocorrida em 1909, em São Paulo, contra a empresa canadense Light \& Power, identificou que para além das disputas empresariais (com os Guinle) e os atritos cotidianos envolvendo a atuação da companhia na especulação imobiliária, a revolta teria sido ocasionada pela desorganização de um modo tradicional de economia ligada ao transporte de cargas e mercadorias com a introdução dos bondes. O autor mobiliza o conceito de economia moral para a compreensão desse processo.

No caso de Fortaleza, contudo, não havia disputa empresarial em curso. A Light, naquela cidade, detinha o monopólio tanto do tráfego de bondes quanto da produção de eletricidade (só no final dos anos 1920, com o início da circulação dos ônibus, é que os tramways da companhia inglesa teriam concorrentes) e não podemos falar de insatisfações associadas à quebra de setores tradicionais de comércio.

Recuando um pouco mais no tempo, a análise de Sandra Graham sobre a Revolta do Vintém demonstrou como esse episódio modificou a dinâmica política na corte imperial durante o Segundo Reinado. Segundo a autora, um número considerável de "moradores da cidade", normalmente desconsiderados na arena da política parlamentar, teriam conseguido, por meio da "violência de rua", participar da "equação política". ${ }^{54}$ Tratando da mesma revolta, Ronaldo Pereira de Jesus sugeriu, seguindo os passos de José Murilo de Carvalho, a inserção desse momento em um quadro mais amplo de descontentamento popular, com a identificação de padrões de revolta entre a monarquia e a república e de um "imaginário político popular". 55

Vamos começar observando os debates de 1924, quando a Light apresentou a proposta de elevar as tarifas dos bondes. Naquela ocasião, foram chamados para negociar representantes de várias associações da capital: Centro dos Importadores, Associação Comercial, Centro Artístico Cearense, ${ }^{56}$ Phenix Caixeiral e outras, conjuntamente aos representantes da Light e do governo estadual e municipal. O caso era polêmico, pois não era novidade que o custo de vida estava em crescimento. A imprensa não deixou de mencionar a "dura e cruel carestia"57

53 SAVIO, Marco Antonio Cornacioni. "Economia moral e revolta: o caso dos bondes em São Paulo." Projeto História, São Paulo, n. 34, p. 133-146, jun. 2007.

54 GRAHAM, Sandra. "O Motim do Vintém e a cultura política no Rio de Janeiro." Revista Brasileira de História, São Paulo, v. 10, n. 20, 1991, p. 220.

55 JESUS, Ronaldo Pereira de. "A Revolta do Vintém e a crise na monarquia." História Social, Campinas, n 12, p. 73-89, 2006.

56 O Centro Artístico Cearense, associação "de resistência e benefício", foi fundado em 1904, possuía sede própria na Rua Tristão Gonçalves e mantinha uma escola noturna "para meninos pobres, de ambos os sexos". Almanaque do Ceará para o ano de 1924. Fortaleza: Tipografia Gadelha, 1924, p. 208.

57 O Nordeste, Fortaleza, 1 fev. 1924, p. 2. 
que devia ser levada em consideração, pois uma elevação das tarifas apertaria "sensivelmente a bolsa dos pobres". ${ }^{8}$

Em reunião no Centro Artístico, a assembleia recusava o aumento das tarifas considerando o"sentir da população que sofrehorrivelmente coma atual carestia".59 Sem adentrarmos nos pormenores dos debates, foi ficando evidente, ao longo das negociações, que a postura das agremiações de trabalhadores (Centro Artístico e Phenix, principalmente) marcava posição decididamente contrária à elevação das tarifas sem uma contrapartida justa para garantir os interesses dos mais pobres. O Centro Artístico, por exemplo, colocava como condições para aceitar a mudança a manutenção da tarifa para os veículos de $2^{\mathrm{a}}$ classe, "que não poderão trafegar, sob pretexto algum, sem o respectivo reboque", ${ }^{60}$ além de outras exigências envolvendo a melhoria no serviço. Por outro lado, as associações patronais e o governo, mesmo reconhecendo as dificuldades que isso poderia causar, inclinavamse para aceitar as propostas da companhia inglesa. No decorrer dos encontros, as associações de trabalhadores foram sendo excluídas das reuniões e, portanto, sua opinião sobre o assunto passou a ser ignorada. A proposta da empresa tornouse vitoriosa nas negociações, não sendo feito, porém, qualquer alarde mais sério quanto ao resultado.

Como fica evidente, a proposta da Light foi submetida a uma avaliação que, a princípio, contava com a participação de representantes dos trabalhadores. Como tais, esses indivíduos rejeitaram as medidas como francamente prejudiciais aos interesses de caixeiros, operários e jornaleiros. Alternativas foram buscadas para resguardar os interesses dos mais pobres, considerando o quadro de carestia na época. As organizações de trabalhadores foram, aos poucos, excluídas da comissão de negociação e, mesmo com ressalvas, a reivindicação da Light foi aceita. Perante a população e, em especial, perante os representados das associações excluídas, ficava evidente que o espaço real - pelos mecanismos legais e institucionais de negociação - para suas demandas e interesses era muito restrito. Era como se um fosso estivesse aberto entre os trabalhadores e o governo. Se não havia, portanto, oportunidade para uma negociação nesses termos, restava uma opção já conhecida da população citadina de Fortaleza: uma contestação violenta das medidas que os prejudicavam. Com a revolta, a política de gabinetes, que excluía os trabalhadores, era rechaçada. Afirmamos aqui tratar-se de uma opção já conhecida posto que, em 1912, uma revolta popular promoveu a deposição da oligarquia Accioli. ${ }^{61}$ Essa experiência sem dúvida compunha a memória de vários habitantes da capital como demonstração cabal das possibilidades e potencialidades da ação coletiva direta e da força do povo. Quando as novas medidas foram executadas, sequer as melhorias ou contrapartidas sugeridas foram contempladas. Diante disso a fúria popular explodiu.

Essa revolta explicitou o crescente processo de ampliação urbana da capital. 0 aumento no número de habitantes, em grande medida decorrente das constantes migrações campo-cidade ${ }^{62}$ ocasionadas pelas secas, e o simultâneo processo de

58 O Nordeste, Fortaleza, 2 fev. 1924, p. 3.

59 O Nordeste, Fortaleza, 4 fez. 1924, p. 2.

60 Diário do Ceará, Fortaleza, 14 fev. 1924, p. 1.

61 Sobre esse episódio conferir: ANDRADE, João Mendes de. "A Oligarquia Acciolina e a política dos governadores". In: SOUSA, Simone de. História do Ceará. Fortaleza: Fundação Demócrito Rocha, 1994; SILVA, Antonio Zilmar. "A Oralidade Deitada Sobre o Papel: Homens, Letras e Vozes em Trincheiras. (Movimento armado em Fortaleza, 1911-1912)" (Dissertação de mestrado em História, Pontifícia Universidade Católica de São Paulo, 2004). PONTE, Sebastião Rogério. Fortaleza Belle Époque: reforma urbana e controle social (1860-1930). $3^{\text {a }}$ ed. Fortaleza: Edições Demócrito Rocha, 2001.

62 NEVES, Frederico de Castro A Multidão e a História: saques e outras ações de massas no Ceará. Rio de 
formação de bairros pobres na periferia da cidade (chamados de arrabaldes) tornava cada vez mais imprescindível a utilização do sistema de transporte público. Isso já havia sido percebido antes: "Os desfavorecidos da fortuna, moradores nos pontos mais afastados, não se poderiam transportar por preços dobrados, cujo aumento corresponderia a 10 ou $20 \%$ dos seus salários". ${ }^{63} \mathrm{~A}$ insuficiência de recursos dos vários segmentos da classe trabalhadora não era capaz de comportar facilmente uma elevação dos gastos. O afastamento dos locais de moradia em relação aos locais de trabalho demandava um serviço de transporte regular, eficiente e a baixo custo. Se acrescentarmos que a carestia já vinha corroendo os ganhos dos trabalhadores, a situação se torna ainda mais angustiante. Os casos são variados nos anos que antecederam a revolta. Em 1923, os caixeiros reclamavam que, apesar da carestia, "continuavam a receber os mesmos salários", o que "tornava a vida difícil". ${ }^{64} \mathrm{~A}$ assembleia da categoria deliberou reivindicar melhorias salariais, o que não foi obtido. As reclamações contra a ação dos açambarcadores se tornaram comuns. Em 1924, paralelo ao debate sobre o futuro aumento das passagens nos bondes, encontramos os esforços para criação de cooperativas de consumo, estratégia coletiva para driblar as dificuldades provocadas pela elevação dos preços.

Podemos afirmar, portanto, que a revolta em 1925 catalisou e sintetizou um conjunto de demandas e insatisfações tornando-se, simultaneamente, um protesto por melhores serviços públicos, contra a carestia e de crítica à ação governamental, possuindo importantes significações em termos de cultura política.

Em uma cidade que crescia em termos populacionais e espaciais, a deficiência do sistema de transporte tornou-se tema de grande relevância, condensando, talvez, boa parte das expectativas práticas e simbólicas da vida urbana. ${ }^{65}$ Uma revolta pelo direito à cidade, enfim. Foi também uma luta contra a carestia. Essa luta já se manifestava de diversas formas ao longo dos anos 1920: queixas que ganhavam as páginas da imprensa contra o preço exorbitante de certos gêneros, reclamações contra a ação de açambarcadores e especuladores em geral, iniciativas de criação de cooperativas de consumo, reivindicações de aumento salarial que pudessem compensar as perdas provocadas pela elevação do custo de vida e, finalmente, uma luta feroz contra o aumento do preço das passagens de bonde e mudanças enganosas promovidas pela Light que prejudicavam os trabalhadores, situação agravada por ser a única empresa a operar no transporte público.

Por fim, podemos destacar que, se o objetivo principal das ações sociais empreendidas nos dias de revolta não obtiveram o resultado esperado pelos seus principais protagonistas, foi alcançado um êxito parcial. A Light não revogou suas medidas, como sabemos. Ambos os tipos de veículos, com as respectivas tarifas, continuaram a circular de forma alternada pelas ruas de Fortaleza. Somente nos horários de maior fluxo - ao meio-dia e início da noite - circulariam bondes de $1^{\mathrm{a}} \mathrm{e}$ $2^{\text {a }}$ classe simultaneamente, conforme acertado com o governo. Não parecem existir muitas dúvidas sobre as razões desse resultado: as forças de repressão debelaram as ações e movimentos públicos de protesto. O quebra-quebra foi interrompido, os mais "exaltados" foram agredidos violentamente ou detidos, a circulação de boletins foi seriamente dificultada. O governo dava mostras de sua exígua tolerância em relação

Janeiro: Relumé-Dumará; Fortaleza: Secretaria de Cultura e Desporto, 2000.

63 Diário do Ceará, Fortaleza, 10 fev. 1924, p. 1.

64 O Nordeste, Fortaleza, 12 out. 1924, p. 2.

65 Aproveitando de forma livre a sugestão de Sidney Chalhoub, ao comentar a bibliografia que analisa a Revolta da Vacina, podemos dizer que os trabalhadores não só reagiam contra algo, mas também agiam em defesa ou reivindicação de algo. CHALHOUB, Sidney. Cidade Febril: cortiços e epidemias na Corte Imperial. São Paulo: Companhia das Letras, 1996, p. 99. 
às formas autônomas e diretas de ação da população. Paralelamente à dimensão da repressão, que nunca deve ser minimizada, vimos que a dinâmica dos acontecimentos, com a adoção de uma forma ainda mais violenta de atuação, minou a legitimidade dos protestos, ao mesmo tempo em que ofereceu argumentos extras para um cerco ainda maior das forças policiais sobre o ambiente urbano, tornando praticamente inviável o prosseguimento de qualquer forma mais explícita de protesto. Contudo, durante o desenrolar da revolta, o governo estadual tentou se apresentar como mediador, buscando um acordo que, mesmo limitado, pudesse minorar o ímpeto da fúria popular. Podemos pensar que o governante tenha, a certa altura, se sentido acuado a memória da deposição de Accioli em 1912 ainda era bastante viva. Destaquemos que alguns dos principais momentos de fúria popular ocorreram diante de uma ofensiva, real ou presumida, das forças policiais. Aproveitando a instigante reflexão de José Murilo de Carvalho, podemos afirmar que se tratava, também, de uma "defesa do direito dos cidadãos de não serem arbitrariamente tratados pelo governo". ${ }^{66}$

Foi ficando evidente, em vários momentos, uma crítica popular ao posicionamento das autoridades, o que podemos considerar uma nova percepção em termos de cultura política. A ideia de um conluio entre companhia e governo, como vimos, parece ter ganhado força durante a revolta. Os poderes constituídos pareciam se curvar aos interesses da poderosa companhia inglesa em detrimento das demandas dos mais pobres, e isso se tornou inaceitável. A interpenetração entre poder econômico e poder político passa a ser objeto de contestação mais ou menos explícita, sendo manifesta a descrença em relação a algum tipo de medida positiva em prol da coletividade por parte do governo, já que existiam elementos da administração pública diretamente ligados à companhia inglesa (o secretário do Interior era advogado da Light). Vale destacar que nenhuma nova tentativa de elevação das tarifas de bondes foi tentada nos anos seguintes, o que pode ser creditado ao impacto daqueles dias de protesto.

A repercussão desse episódio deixou marcada a imagem do desembargador Moreira da Rocha - o "Moreirinha" - cujo governo ficou associado ao trato violento em relação ao povo. Anos depois, a imprensa não deixava de lembrar o assunto:

\footnotetext{
Como toda nossa população sabe e V. S. não deve ignorar a 'Light' além de ser uma companhia que só muitos males tem feito ao Ceará, constituiu-se de há muito tempo em forma de discórdia entre o povo e o governo.

V. S. deve estar lembrado de que a impopularidade do desgoverno Moreirinha começou pelo espaldeiramento, na praça pública, ao povo pela polícia daquele nefasto quadriênio (...)

E a 'Light' triunfou esteada no chanfalho policial daquela época, manetada por autoridades discricionárias. ${ }^{67}$
}

Apesar da momentânea vitória - se assim podemos dizer - a Light teria que lidar, daí pra frente, com um estado de ânimo popular sempre tendendo contra a companhia. O volume de queixas só faria crescer nos anos seguintes:

Fosse em outro estado do Brasil, que não o Ceará, esta companhia da 'Light' ou havia entrado nos trilhos, mudando de gerência e subgerência, ou então já estaria reduzida a bissulfato de soda ou qualquer droga de nome arrevesado.

66 CARVALHO. Os bestializados, p. 139.

67 O Ceará, Fortaleza, 2 set. 1928, p. 9. 
Diariamente, a imprensa de Fortaleza vem registrando os frequentes abusos desta companhia, a propósito de tráfego e a propósito de luz, enquanto as reclamações surgem a cada momento aos ouvidos de seus dirigentes que nunca procuram atender às reclamações justas das partes.

Referida companhia é um sindicato da mais vil exploração, não cumprindo nenhuma das resumidas cláusulas do contrato firmado com o governo do Estado. ${ }^{68}$

Em outra ocasião surge o epíteto de "polvo" atribuído à companhia:

\section{A LIGHT É UM DOS MAIORES POLVOS DE FORTALEZA}

(...)

A população desta capital já não pode mais suportar as sangrias que a 'Light' lhe vem fazendo.

Todos os serviços dessa companhia não correspondem, de maneira nenhuma, aos imediatos interesses da cidade.

O serviço de 'tramways' é o mais deficiente que imaginar-se possa.

Hoje, pode-se afirmar que, em Fortaleza, não existem bondes de $1^{\text {a }}$ classe. Os que trafegam são apenas, de $5^{\text {a }}$ e $8^{\text {a }}$ classe. ${ }^{69}$

Esse adjetivo - "polvo" - se tornaria comum tanto que, em 1929, durante a greve dos trabalhadores da companhia, seria largamente utilizado. As manifestações de apoio aos grevistas (perceptíveis, por exemplo, por meio de donativos) por parte de várias categorias e diversos setores da população, de certa forma, também podem ser creditadas - logo após a solidariedade classista, logicamente - à animosidade e indisposição popular em relação à Light desde 1925, pelo menos. ${ }^{70}$ Perto do final da década, o monopólio da Light no transporte público seria quebrado com o início da circulação dos ônibus na capital. Ainda assim, a companhia continuaria sendo uma presença forte na cidade (adquirindo o direito de iluminação pública na década de 1930) e seus tramways permaneceriam na paisagem urbana até 1947.

Recebido em 24/07/2016

Aprovado em 30/01/2017

68 O Ceará, Fortaleza, 15 abr. 1928, p. 16.

69 O Ceará, Fortaleza, 4 maio 1928, p. 3.

70 PARENTE, Eduardo Oliveira. "'Abaixo o imperialismo explorador do nosso sangue': política e cultura operária durante a greve dos trabalhadores da Light em 1929". In: VIANA JUNIOR, Mário Martins; BARBOSA, Carlos Henrique, ALVES, Raquel da Silva. (orgs.) Fortaleza sob outros olhares: trabalho e política. Fortaleza: Expressão Gráfica, 2011, p. 87-124. 